\title{
Research Paper Forecasting gold prices in India using ARIMAX and machine learning algorithms
}

\author{
- P. Sai Shankar and M. Krishna Reddy
}

See end of the paper for authors' affiliations

Correspondence to :

P. Sai Shankar Department of Statistics, University College of Science, Osmania University, Hyderabad (Telangana) India Email: saishankar26@gmail .com

Paper History :

Received : 21.05.2020;

Revised : 26.07.2020;

Accepted : 28.08 .2020

\begin{abstract}
Forecasting is a function in management to assist decision making. It is also described as the process of estimation in unknown future situations. In a more general term it is commonly known as prediction which refers to estimation of time series or longitudinal type data. The main object of this paper is to compare the traditional time series model with machine learning algorithms. To predict the gold prices based on economic factors such as inflation, exchange rate, crude price, bank rate, repo rate, reverse repo rate, gold reserve ration, Bombay stock exchange and National stock exchange. Two lagged variables are taken for each variable in the analysis. The ARIMAX model is developed to forecast Indian gold prices using daily data for the period 2016 to 2020 obtained from World Gold Council. We fitted the ARIMAX $(4,1,1)$ model to our data which exhibited the least AIC values. In the mean while, decision tree, random forest, lasso regression, ridge regression, XGB and ensemble models were also examined to forecast the gold prices based on host of explanatory variables. The forecasting performance of the models were evaluated using mean absolute error, mean absolute percentage error and root mean squared errors. Ensemble model out performs than that of the other models for predicting the gold prices based on set of explanatory variables.
\end{abstract}

KEY WORDS : Gold prices, ARIMAX, Lag variables, Random forest model, XGB model, Ridge regression, Lasso regression, Ensemble model

How To Cite This Paper: Sai Shankar, P. and Krishna Reddy, M. (2020). Forecasting gold prices in India using ARIMAX and machine learning algorithms. Internat. Res. J. Agric. Eco. \& Stat., 11 (2) : 299-310, DOI : 10.15740/HAS/IRJAES/11.2/299-310. Copyright@2020:Hind Agri-Horticultural Society.

\section{INTRODUCTION :}

Historically, gold had been used as a form of currency in various parts of the world including USA. In recent times also, gold has maintained its value and has been used as a means for assessing the financial strength of a country. Big investors have also been attracted to this precious metal and invested huge amounts in it. Recently, emerging world economies, such as China, Russia and India have been big buyers of gold, whereas,
USA, South Africa and Australia are among the big seller of this commodity. Chinese and Indian traditional events also affect the price of the gold. In that time more money is poured for purchase of this commodity. Small investors also find this commodity for safe investment rather than alternate investment options, which bear in-built investment risks. Internal financial conditions of the aforementioned countries play a vital role for setting spot rates for gold. Governmental investments in gold are largely decided by their financial conditions and interest 